\section{B A Institute of \\ YK Business Administration \\ 六下 \\ Karachi \\ Leadership and Ideas for Tomorrow}

Business Review

Volume 3 Issue 2 July-December 2008

$7-1-2008$

\title{
Leveraging on knowledge management approach for effective risk management in building projects
}

\author{
Faisal Manzoor Arain \\ Southern Alberta Institute of Technology, Canada
}

Follow this and additional works at: https://ir.iba.edu.pk/businessreview

Part of the Business Commons

\section{(c) (i)}

This work is licensed under a Creative Commons Attribution 4.0 International License.

\section{Recommended Citation}

Arain, F. M. (2008). Leveraging on knowledge management approach for effective risk management in building projects. Business Review, 3(2), 1-16. Retrieved from https://doi.org/10.54784/1990-6587.1151

This article is brought to you by iRepository for open access under the Creative Commons Attribution 4.0 License and is available at https://ir.iba.edu.pk/businessreview/vol3/iss2/5. For more information, please contact irepository@iba.edu.pk. 


\title{
ARTICLE
}

\section{Leveraging on Knowledge Management Approach for Effective Risk Management in Building Projects}

\author{
Faisal Manzoor Arain \\ Southern Alberta Institute of Technology, Canada
}

\begin{abstract}
This paper aims to introduce a new approach utilizing knowledge management to simplify the process of risk management, so as to enhance the knowledge sharing and promote its application in the construction industry. Decision making is a significant characteristic that occur in each phase of a project. Often, these decisions will, or can affect the other tasks that will take place. To achieve an effective decision making process, project managers and the other personnel of one project need to have a general understanding of other related or similar past projects. Risk management is important to support decision making at the early stage in a project. The technique of knowledge management is particularly useful for project risk management, as the process involved in risk management largely depend upon previous experience. It is useful to be able to accumulate previous knowledge and share this with other project participants. However, because of the complexity of construction project, knowledge acquisition, sharing and transfer are difficult. A case-based reasoning intelligent system that simulates the process of human reasoning is presented as an appropriate solution to managing knowledge in relation to project risks. This would provide the professionals with requisite knowledge to make more informed decisions and to take proactive measures for reducing potential risks and variations in ongoing and future projects.
\end{abstract}

Keyword: Management, Knowledge-base, Buildings, Projects, Risks.

\section{INTRODUCTION}

Construction projects have a poor reputation for achieving time and cost goals. Risk management is important as it provides a chance for project participants to review the whole project by communicating through a common language, to understand better and access the potential problem and then allocate it through a reasonable manner. It can enhance the communication among project participants and improve the relationship. However, despite some of successful established theories, risk management is still not able to satisfy practice. Previous risk analysis researches focused on quantification stage. However, some of the qualitative processes are more important, such as risk identification. Successful qualitative analysis usually depends 
on human experts, their knowledge and their creativity. Therefore, to improve risk management must improve knowledge sharing.

This paper introduces a more qualitative risk management approach through managing knowledge in relation to project risks. It illustrates the relationship between current qualitative methods and knowledge sharing and transfer, and compares the similarity of human problem solving procedure and case-based reasoning (CBR). The purpose is to simplify risk management process, provide reliable evidence to support decision making and finally lead to a broader application of project risk management.

\section{RISK MANAGEMENT IN CONTEMPORARY PRACTICE}

Despite some successful achievements, there are still barriers exist in current risk management methods that impede its application in real practice. To overcome these limitations, it is much useful to manage risks from understanding the knowledge in relations to project risks.

\section{LIMITATION OF CONTEMPORARY METHODS}

Construction projects are complex because they involve many human and nonhuman factors and variables. They usually have long duration, various uncertainties, and complex relationships among the participants. To identify and analyze potential risks that could happen in a project as early as possible can enhance the assessment of project. After a survey regarding general contractors and project management of the construction industry's risk analysis and management techniques, Akintoye and Macleod (1997) presented that risk management is essential to construction activities in minimizing losses and enhancing profitability. According to ICE and FIB (1998), the benefits gained from project risk management are: an increased understanding of the project and the risks in a project and their possible impact, an independent view of the project risks which can help to justify decisions and enable more efficient and effective management of the risks and an understanding of how risks in project can lead to the use of a more suitable type of contract.

The main problem of current risk management research is the difficulty in promoting research achievements into real application efficiently. According to World Bank 1990's annual review, 63\% out of 1778 projects between 1974 and 1998 had experienced significant cost overrun. A study of more than 8,000 projects in 1994 conducted by Standish Group found that only 16\% were able to satisfy (Hartman, 1997). In 1998, a survey carried out by Leunga et al. (1998) shows risk management approaches are not widely accepted in Hong Kong projects. The major limitations identified in applying risk management come from three angles: 


\section{TIME AND COST}

According to Raftery (1994), many professionals who have accumulated some experience of carrying out risk analysis on projects find that the identification stage is the most time consuming. In addition, the time involved in using risk management approaches, training the relevant staff, learning and choosing available risk management methods, obtaining input estimates and assessment of their probabilities, understanding and interpreting outcomes of risk management process all need time. Apparently, to carry out risk analysis usually need more advance technique and/or more labor involvement, which may need additional investment.

\section{COMPLEXITY}

Because of the complexity of risk, risk management is more sufficient when combine several methods together. The technique involved in these methods includes mathematics, statistics and operation research, which may be difficult for all project participants to understand. It is even difficult to use it correctly. Moreover, different method suits to different purpose and project futures, not every one think it is necessary to learn all of these.

\section{ACCURACY}

Identifying and quantifying risk is about trying to forecast the unknown (Carter, et al., 1996; Arain, 2005a). Risk identification is the fundamental stage for risk management. It is usually based on some assumptions. As a result, the elements used to carry out quantitative analysis may inaccurate or insufficient and uncertainty will be all along with the analysis process, till the end of the project. This will dramatically influence the accuracy of the risk analysis results.

\section{RISK MANAGEMENT IN RELATION TO KNOWLEDGE}

Having identified the limitations of the current methods, it is a matter to seek another solution and evaluate the feasibility. Qualitative approach based on knowledge seems much better. However, the influence of human behavior raises another issue.

\section{THE IMPORTANCE OF QUALITATIVE ANALYSIS}

Traditionally, risk management is carried out by the identification of potential risk sources, the evaluation of probability and possible loss, and the allocation amongst the project participants. According to a study taken by the Confederation of British Industry (CBI) in 1994, only about one-quarter used quantitative methods to assess project risk, with the majority relying on subjective judgment (ICE and FIB, 1998). An important part of risk management activity lies in harnessing the experience and 
knowledge of the entire management population in a project to anticipate and overcome risks, rather than mathematical and complex statistical simulations (Carter, et al., 1996). Smith (1999) points that one of the main obstacles when introducing risk management to an organization is the lack of openness and communication within the organization. When carrying out communication, textual information as the basic everyday language is easier for the project participants to understand and spread. Therefore, qualitative analysis will be much easier for human participants to accept instead of to understand various complicated risk quantification methods.

\section{THE INFLUENCE OF HUMAN BEHAVIOR}

Qualitative risk analysis is largely based on experts' experience. Identifying risks internally or externally to the project requires that the analyst be systematic, experienced and creative and the identification of risks is about making the best use of the information and experience available at the time of making the decision (Raftery, 1994). Risk perception is generally influenced by people's belief, attitudes, judgment and feelings (Akintoye and Macleod, 1997). However, people's assumptions and perceptions may be inaccurate and inconsistent (Raftery, 1994). Ritchie and Marshall (1993) have identified factors influencing the formation of risk perception including educational background, practical experience, an individual's cognitive characteristics, the availability of information, and peer group influence. Schettler et al. (2001) presented the people problems of construction risk management are currently being subjected to a substantial research effort directed mainly at the establishment of subjective probabilities, the exploration of heuristics and biases, and the nature and extent of risk management practices in the construction industry.

Humans have limitations in coping with complex information. Pender (2001) asserts that about nine decision attributes is all that a person can effectively encompass at one time and they made the decision averagely based on the most three similar decisions they made. As a result, to manage the knowledge in relation to projects risks, more importantly, would find a knowledge management scheme which suits to its characteristics.

\section{KNOWLEDGE MANAGEMENT}

Recently, knowledge management attracts significant attention in the field of project management, especially in the view of organization strategy and human resources. What is knowledge and knowledge management? Whether it is useful for project risk management? And how it can be used to manage project risks? 


\section{KNOWLEDGE AND KNOWLEDGE MANAGEMENT}

\section{DEFINITION}

Davenport and Prusak (1998) defined knowledge as a "fluid mix of framed experience, values, contextual information, and expert insight that provides a framework for evaluating and incorporating new experiences and information". Knowledge is the whole body of cognitions and skills which individuals use to solve problems (Probst, et al., 1999). It is a complex concept which consists of information and skills acquired through experience; truth and belief, perspective and judgments, expectations and methodologies (Egbu, et al., 2003). Comparing with project risk data and information, the knowledge relates to project risks is a deeper understanding and integration concept as shown in Figure 1.

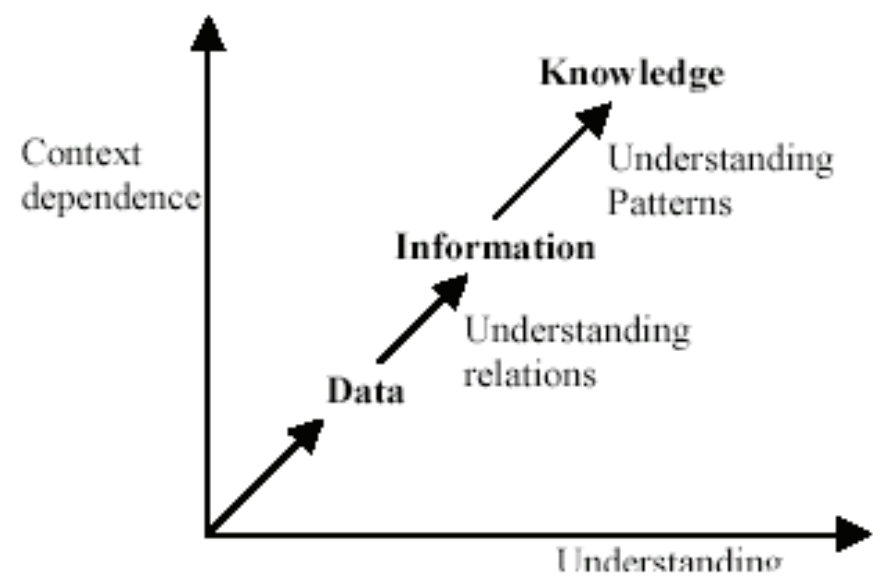

Figure 1 The relationship of context to understanding (Egbu, et al., 2003).

Knowledge management involves the acquisition, storage, retrieval, application, generation, and review of the knowledge assets of an organization in a controlled way (Watson, 2003; Arain, 2005a). Knowledge management enables the creation, communication, and application of knowledge of all kinds to achieve business goals (Tiwana, 2000; Arain and Low, 2006a). Managing knowledge relevant to project risks will help capture, accumulate, access, exchange and implement this knowledge to cope with risks in new projects. 


\section{KNOWLEDGE SHARING AND TRANSFERRING}

A successful knowledge management initiative will install a learning and knowledge sharing culture and environment, provide vision and effective leadership to overcome learning barriers (Maqsood, et al., 2003; Arain, 2005b). Sharing knowledge in project risk management can reduce time and effort, speed up decision-making process, provide an effective way of inducting new staff, encourage the use of knowledge and promote collaboration, capture knowledge for organization use and encourage the transfer of best practice (Kermally, 2002).

Knowledge can be classified as tacit knowledge and explicit knowledge. Tacit knowledge is personnel knowledge and in practice it is difficult to communicate fully to others, it has a technical as well as cognitive dimension; while, explicit knowledge is the knowledge that has been articulated, coded and recorded (Kermally, 2002; Arain and Low, 2006a).

Nonaka and Takeuchi (1995) presented the four modes of knowledge conversion:

- Socialization: acquiring knowledge from design engineer, site manager, etc;

- Externalization: converting tacit knowledge into explicit knowledge;

- Combination: transforming explicit knowledge into future explicit knowledge by integrating different bodies of explicit knowledge;

- Internalization: transferring explicit knowledge into tacit knowledge.

The methods used in different knowledge converting modes can be used formally or informally in the project risk management as shown in Table 1:

\begin{tabular}{|c|c|c|c|}
\hline Socialization & Externalization & Combination & Internalization \\
\hline $\begin{array}{l}\text { Brainstorming, } \\
\text { informal } \\
\text { meeting, } \\
\text { discussions, } \\
\text { dialogues, } \\
\text { observation, } \\
\text { training. }\end{array}$ & $\begin{array}{l}\text { Meeting, } \\
\text { workshops, } \\
\text { building } \\
\text { hypotheses, } \\
\text { models. }\end{array}$ & $\begin{array}{l}\text { Virtual library, } \\
\text { reports, } \\
\text { publications, } \\
\text { conferences. }\end{array}$ & $\begin{array}{l}\text { Facilitation skills, } \\
\text { Knowledge zone, } \\
\text { client/contractor } \\
\text { feedback review, } \\
\text { development } \\
\text { counseling. }\end{array}$ \\
\hline
\end{tabular}

Table 1 Methods to carry out the knowledge converting modes

Most of these methods rely upon non-numerical information. Therefore, qualitative methods are more suitable in coping with knowledge in relation to project risks. 


\section{KNOWLEDGE SHARING AND TRANSFERRING IN PROJECT RISK MANAGEMENT}

Qualitative methods usually analysis risks by delivering a great deal of relevant knowledge. Various such methods have already been introduced to the construction project, such as examining historical documents, brainstorming and Delphi, which compared with three methods that project participants acquire and share knowledge:

\section{READING AND WRITING-THROUGH PAPER WORK}

Examining historical documents is the most essential and basic approach to acquire knowledge relates to project risks, as shown in Figure 2. The knowledge transfer is along with the transfer of project documents and it is shared when other project participants read it. Historical data is valuable for getting a conception about risks in previous projects (Artto, 1997; Arain and Low, 2006a). The previous project data, records, common and failure, plus the project managers' knowledge, experience and judgment can provide suitable suggestion when carry out risk identification. Therefore, it is necessary to learn from the experience, both success and failure. Furthermore, historical data provides an initial list of possible risks for brainstorming discussion.

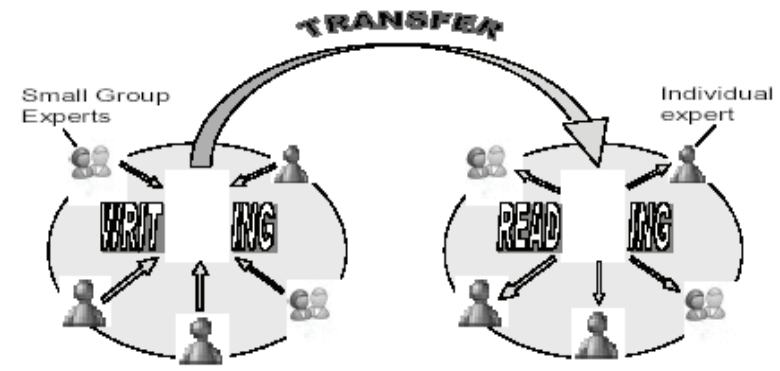

Figure 2 Transferring and sharing knowledge by reading and writing

\section{TALKING-THROUGH FACE TO FACE COMMUNICATION}

Brainstorming is a typical method of people sharing and transferring knowledge through face to face communication. Figure 3 illustrates the format of this type of method. 


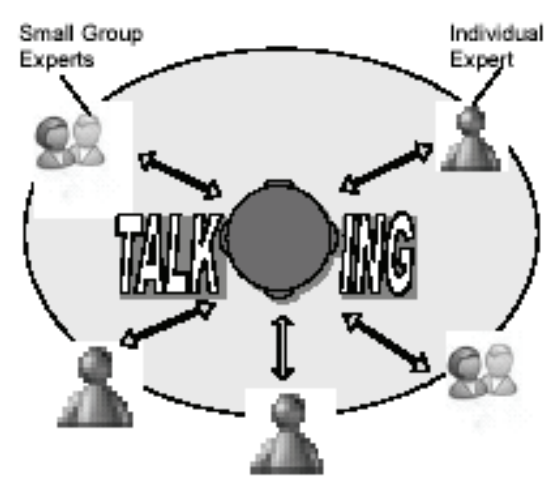

Figure 3 Sharing and transferring knowledge by talking

A formal brainstorming is sometimes used in this context. Outlandish suggestions are encouraged (Raftery, 1994). Brainstorming involves the collective generation of ideas by a group comprising key project personnel and others in an environment free of criticism (Merna and Njiru, 2002; Arain and Low, 2006b).

The underlying principles are that: group thinking is more productive than individual thinking. Brainstorming encourages wide ideas and avoidance of criticism 'silly' ideas till the end. The most promising ideas generated are then selected, built on and combined, developed and verified.

\section{INTEGRATED COMMUNICATION}

Delphi is a well-known method of using group judgments in project risk forecasting. It provides a communication process allowing a group of individuals as a whole to deal with complex problems.

Basically experts answer questionnaire individually for each round; the feedback will be received from the coordinator to guide the next round decision making. Smith (1999) addressed the procedure: "it starts with the formation of a team of experts that represent all aspects of the project; the experts meet and formulate an exact definition of the risk that being considered. They then discuss the risk, paying particular attention to its causes and the interdependencies it has within the project. Subsequently, they give their opinions as to the probability of occurrence of the risk and the impact of the risk on the project, should it occur. The experts can also give a cost assessment of the risk based on the probability of occurrence and possible impact". 


\section{LIMITATIONS OF EXPERT KNOWLEDGE}

Kermally (2002) stated that without effective communication, tacit knowledge remains tacit and organizations lose out. Three knowledge sharing and transferring methods discussed above have various limitations:

- Project documents may not well record, so it might not able to provide as much as possible information that project participants expected. For instance, only 438 of 2791 World Bank projects in transportation, energy and mining and public sector development have risk assessment in its project appraisal document.

- The knowledge relates to project risks is difficult to acquire, because construction project is long duration, the number of projects that an expert involve in is limited. Moreover, the transferring of the experts' knowledge is another issue. Because different experts have different background and experience, humans are influenced by psychological factors and environment they involved. It is difficult to transfer knowledge from one to another exactly the same. The key limitation of brainstorming is peer pressure.

- Delphi somehow overcomes the peer pressure, but the involvement of experts can not guarantee and it is time consuming.

A method is useful if only the user can accept it. To promote the application of risk management in construction projects, we need an easy understandable, easy accessible, easy to communicate, common acceptable and reliable approach. Risk management in fact is a process of managing knowledge. But knowledge is generated within one project and then buried in unread reports and arcane filling system, or lost because of people move on (Carrillo and Anumba, 2002; Arain and Low, 2006c). Furthermore, the knowledge holding by human experts is always influenced by subjective judgment and intuition. Leunga et al. (1998) introduced a rule-based system to identify project risks, however the rule based system are too restrictive to handle tacit knowledge (Watson, 2003). In addition, these rules may not be fully understood or accepted by the other project participants. The knowledge management activities is identified as generate, propagate, locate, capture, access, maintain and use of knowledge. CBR can well fit these stages.

\section{CASE-BASED REASONING APPROACH}

This section explains how CBR satisfied the requirements of a knowledge management system, and in what way it suppose to work in managing project risks. 


\section{WHY CBR?}

To manage knowledge from human experts, it is necessary to understand the way that human reasoning and make decision. In order to comprehend the human problem solving process, Holyoak (1987) distinguished two different types of operations that are applied during a thinking process: the human capability reasoning as making conclusion by interpreting the knowledge stored in our brain; and then guiding the reasoning process so that only the relevant conclusions are inferred. Figuring out the common features of human solving problems and sharing and transferring knowledge process, processing the raw information, picking up useful patterns, remembering previous similar situation, comparing related features, making decision rely upon the similarity, these perfectly match the reasoning process of CBR. As a result, CBR is identified as an appropriate approach to fit the demand of project risk knowledge management.

CBR systems, decision support system and contextual information retrieval systems, which provide the needed historical base from past experience that help make decisions rapidly and accurately (Tiwana, 2001). Comparing with other Artificial Intelligent (AI) systems, CBR has the advantage of coping with textual information, reasoning through uncompleted knowledge, tolerance for complexity, and low expert dependence. Moreover, the process of CBR is more similar with the way that human experts reasoning and making decisions.

\section{CBR CYCLE FOR PROJECT RISK MANAGEMENT}

The process of how CBR system works in project risk management is shown in Figure 4. The information of previous projects is processed to knowledge storing in a knowledge base. When new project comes, it is first translated to the similar project description form as the cases storing in the knowledge base. It then retrieves the knowledge base to find similar previous projects, reuses the risks identified and the management method, and revises these solutions to come up with suggested risks and respond strategy. This preliminary suggestion is reviewed by human experts, and then a new final report of identified risk for this project and relevant respond strategy is provided. This solution accompanies with the new project description then is retained to the knowledge base as a piece of new knowledge for the future use. The refine is more about the maintenance of knowledge base, to update the information, such as when the project have finished, to re-evaluate the identified risks and respond strategy and then revise the knowledge base.

In CBR system, project is described by attributes. The result of retrieving process relies on past cases with attributes that match the current case. The matching scheme depends on varying degree of importance as indicated attributes by different matching weights. A search engine then searches through all the cases in the case 
base and retrieves those that match closely. As new cases are added, the CBR becomes increasingly powerful and accurate.

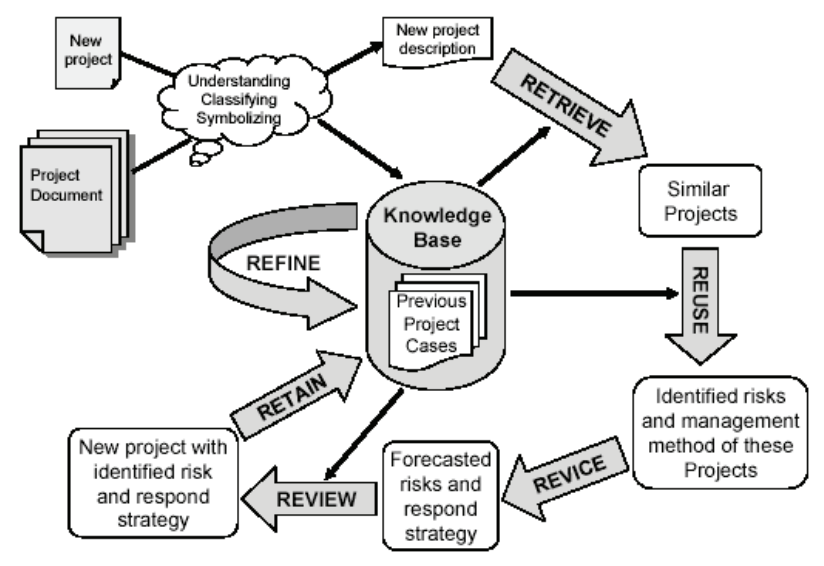

Figure 4 Project risk management CBR procedure

\section{FINDINGS}

The issue of current risk management is the inadequate application. Good risk management depends on sufficient previous experience. However, the knowledge held by individual or small group of experts sometimes is inadequate to support making sufficient risk forecasting and risk respond decision. In addition, humans have limited capability to cope with complex information. CBR as a paradigm to simulate the process of human solving problems, is particular useful for managing risks in relation to project risks. It reasoning by remembering previous risks and allocation strategy in similar projects and then generates a potential solution for the new project.

The undertaken research currently carried out by the author has put it into evaluation by using project data from institutional building projects in Singapore. It is important to understand that this system for the management of risks and variations is not designed to make decisions for users, but rather it provides pertinent information in an efficient and easy-to-access format that allows users to make more informed decisions. Furthermore, this system does not try to take over the role of human experts or force them to accept the output of the system; instead, it aims to provide more relevant evidence to facilitate human experts making final decisions. 


\section{CONCLUDING REMARKS}

Decision making is a significant characteristic that occur in each phase of a project (Arain and Assaf, 2003; Arain, 2005a). In almost every stage, decision making is necessary. Often, these decisions will, or can affect the other tasks that will take place. To achieve an effective decision making process, project managers and the other personnel of one project need to have a general understanding of other related or similar past projects (Arain, 2005b; Arain and Low, 2006a). This underscores the importance of having a good communication and documentation system for better and prompt decision making during various project phases. Eventually, the main focus of future work could be the development and validating of a knowledge-based decision support system for effective management that would enable the professionals to be aware of factors which initiate risks and variations, their frequent effects and effective controls (Arain and Low, 2006b). This would provide the professionals with requisite knowledge to make more informed decisions and to take proactive measures for reducing potential risks and variations in ongoing and future projects.

This paper has presented research into the development of an approach for a knowledge-base decision support system for management. This study is part of a larger research study that is being carried out in Singapore for developing a knowledge-based system for effective management of variations in institutional buildings (Arain and Low, 2006c). The knowledge-base system will be developed through collecting data from source documents of the institutional projects completed, questionnaire surveys of the developers, consultants and contractors and in-depth interview sessions with the professionals who were involved in these institutional projects. The system is being developed, for a governmental organization (developers) that is responsible for developing institutional building projects in Singapore, for effective management of possible variations and risks in the projects.

\section{BENEFICIAL OUTCOME}

The study presented in-depth research into development of a knowledge-based management system for effective management of risks in projects. This may assist professionals in analyzing risks and variations, and selecting the appropriate controls for minimizing their adverse impacts. Hence, the study is valuable for all the professionals involved with developing the building projects. The litmus test for successful management should not be whether the project was free of risks and variations, but rather, if risks and variations were considered and resolved in a timely manner to the benefit of all the parties and the project (Arain, et al., 2004). Furthermore, by having a systematic way to manage risks and variations, the efficiency of project work and the likelihood of project success should increase. The 
system emphasized on sharing the lessons learned from existing projects with project teams of future projects. The lessons learned should be identified throughout the project life cycle and communicated to current and future project participants (Arain, et al., 2004). The study would assist building professionals in establishing an effective management system. The system would be helpful for them to take proactive measures for reducing risks and variations in projects. Hence, the study is valuable for all the professionals involved with building projects. Furthermore, this study also contributed to knowledge as the in-depth research into development of the system, can be used by future researchers to carry out studies on the development of similar management systems for other aspects of management in any specific type of projects.

\section{ACKNOWLEDGEMENTS}

The author would like to thank and acknowledge the National University of Singapore for making available the data needed to carry out the present study. The author also wishes to thank Architect Sarwat Abbasy for her very helpful and constructive comments.

\section{REFERENCES}

Akintoye, A. S. and MacLeod, M.J. (1997) Risk analysis and management in construction, International Journal of Project Management, 15(1), pp 31-38.

Arain, F.M. (2005a) Potential barriers in management of refurbishment projects, Journal of Independent Studies and Research, 3(1), pp. 22-31.

Arain, F.M. (2005b) Strategic Management of variation orders for institutional buildings: Leveraging on information technology, Project Management Journal, PMI, 36(4), pp.66-77.

Arain, F.M. and Assaf, S. (2003) Project design and construction interface dissonances, Journal of Research in Architecture and Planning, (2), pp.69-80.

Arain, F.M., Assaf, S.A. and Low, S.P. (2004) Causes of discrepancies between design and construction, Architectural Science Review, 47(3), pp. 237-249.

Arain, F.M. and Low, S.P. (2006a) A framework for developing a knowledge-based decision support system for management of variations in institutional buildings, Journal of Information Technology in Construction (ITCon), Special Issue Decision Support Systems for Infrastructure Management, 11(1), pp. 285-310. 
Arain, F. M. and Low, S. P. (2006b) Value Management through a knowledge based decision support system for managing variations in educational building projects, International Journal of Construction Management, 6(2), pp. 81-96.

Arain, F.M. and Low, S.P. (2006c) Knowledge-based decision support system for management of variation orders for institutional building projects, Automation in Construction, 15(1), pp.272-291.

Artto, K.A. (1997) Fifteen years of project risk management applications- where are we going?, Kahkonen, K. and Artto, K.A. Eds., Managing risks in projects. E\&FN Spon, London.

Carrillo, P. and Anumba, C. (2002) Knowledge management in the AEC sector: an exploration of the mergers and acquisitions context, Knowledge and process management, 9(3), pp149-161.

Carter, B., Hancock, T., Morin, J.M., and Ro, N. (1996) Introducing Risk man: the European project management methodology. London.

Davenport, T.H. and Prusak, L. (1998) Working knowledge. Harvard business school press, Boston.

Egbu, C., Hari, S. and Kumar, B. (2003) Knowledge management practice in small and medium enterprises in the construction industry, The 19th Conference of Association of Researchers in Construction Management, Brighton, UK, pp 653-660.

Hartman. F. (1997) Proactive risk management- myth or reality?, Kahkonen, K. and Artto, K.A. Eds., Managing risks in projects. E\&FN Spon, London.

Holyoak, K. (1987) Cognitive Psychology. Shapiro, S.C. Ed., Encyclopedia of Artificial Intelligence, John Wiley and Sons, New York, 115-120.

ICE and FIA (1998). RAMP: risk analysis and management for projects. Thomas Telford, London.

Kermally, S. (2002) Effective knowledge management: a best practice blueprint, John Wiley \& Sons, Chichester.

Leunga, H.M., Chuaha, K.B. and Tummala, V.M.R. (1998) A Knowledge-based System for Identifying Potential Project Risks, International Journal of Management Science, 26(5), pp 623-638.

Maqsood, T., Finegan, A.D. and Walker, D.H.T. (2003) A conceptual model for exploring Knowledge canalization from sources of innovation in construction 
organizations: extending the role of knowledge Management, The 19th Conference of Association of Researchers in Construction Management, Brighton, UK, pp 613621.

Merna, T. and Njiru C. (2002) Financing infrastructure project, Thomas Telford, London.

Nonaka, I. and Takeuchi, H. (1995) The knowledge-creating company: how Japanese companies create the dynamics of innovation, Oxford University Press, Oxford.

Pender, S. (2001) Managing incomplete knowledge: Why risk management is not sufficient, International Journal of Project Management, 113(2), pp 79-87.

Probst, G., Raub, S. and Romhardt, K. (1999) Managing knowledge: building blocks for success. John Wiley \& Sons, Chichester.

Raftery, J. (1994) Risk analysis in project Management. E\&FN Spon, London.

Ritchie, B. and Marshall, D. (1993) Business risks management. Chapman and Hall, London.

Schettler, H., Wieczorek, M.J. and Philip, M. (2001) Operational risks and business continuity: an essayistic overview, SQS AG.

Smith, N.J. (1999) Managing risk in construction project. Blackwell Science, Oxford.

Tiwana, A. (2000) The knowledge management toolkit: practical techniques for building a knowledge management system. Prentice Hall, London.

Tiwana, A. (2001) The essential guide to knowledge management: e-business and CRM applications. Prentice Hal, Upper Saddle River.

Watson, I. (2003).Applying knowledge Management: techniques for building corporate memories. Morgan Kaufmann Publication, London. 
Once a philosopher recognizes that his theoretical objectives coincide with the practical objectives of an entire class; once he realizes that the inhuman conditions he is investigating have already been denounced countless times by this same class - could he ever be content with a few insubstantial ideas, and nothing more?

It is time that we cease defining life in the manner of a Bergson. It is time that we stop living like zombies. From now on, it shall be impossible for any man to make effusive grandiloquent pronouncements to the effect that he loves men, that he has devoted his life to mankind - if, at the same time, he is willing to tolerate their humiliation and suppression. From now on, no man shall have the right to lay before the public plans for the ultimate realization of Man's potential. A person either wants to help men realize their potential here and now, or he does not. To make his choice is a far more radical action than the most devastating philosophical critique. If a thinker refuses to apply his intellect to this struggle for a world where all men will be free to develop all their powers to the fullest, then his loud protestations of friendship for Humanity are meaningless.

But if a thinker is willing to join men in this struggle, he will not have to solve any impossible philosophical conundrums, for men are asking nothing more than the chance to become whole human beings.

Paul Nizan

The Watchdogs, p. 132 